\title{
Epidemiology of attention deficit disorder in Brazil: Implications for the Brazilian legal system
}

\author{
Sergio L. Schmidt ${ }^{1}$, Eunice Do Nascimento Simoes ${ }^{1}$, Guilherme J. Schmidt ${ }^{2}$, Marcela J. Schmidt ${ }^{1}$, \\ Ana Lucia Novais Carvalho ${ }^{3}$ \\ ${ }^{1}$ Laboratório de Neurofisiologia e Avaliação Neurocomportamental, Centro Biomédico, State University of Rio de Janeiro, Rio De \\ Janeiro, Brazil \\ ${ }^{2}$ Instituto de Neurologia Deolindo Couto, Federal University of Rio de Janeiro, Rio de Janeiro, Brazil \\ ${ }^{3}$ Instituto de Ciências da Sociedade e Desenvolvimento Regional, Departamento de Fundamentos de Ciências da Sociedade, Federal \\ University Fluminense, Niterói, Brazil \\ Email: slschmidt@,terra.com.br
}

Received 29 September 2013; revised 29 October 2013; accepted 6 November 2013

Copyright (C) 2013 Sergio L. Schmidt et al. This is an open access article distributed under the Creative Commons Attribution License, which permits unrestricted use, distribution, and reproduction in any medium, provided the original work is properly cited.

\section{ABSTRACT}

In spite of the fact that the legal system adopted in Brazil is codified on the Roman tradition, there is no specific protection in law for people suffering from Attention Deficit Disorder (ADD). In contrast, the law of the United States is largely derived from the common law system and there are two federal laws that guarantee a free appropriate public education and provide services to eligible students with disabilities. They are: Section 504 and Individuals with Disabilities Education Act2. The American Legal System reflects the social demand based on epidemiological studies. In the present investigation, we studied the prevalence of attention disorders in Brazil. The sample included 239 students, rated regarding attention problems with a checklist filled by 45 different teachers. As left-handers show greater problems in the impulsive-hyperactivity domain, we investigated the influence of gender on attention problems using handedness as a covariate. Hand preference was assessed by direct observation. A student was classified into the ADD group if he (she) was rated maximum score in at least six questions concerning impulsivity, hyperactivity, and inattention. Sixty-eight students $(28 \%$ of the total sample) were included in the ADD group. The percentage of males was found to be greater in ADD group as compared to the percentage of males in the normal-control group. The gender effect was not explained by handedness. Our data is similar with other studies. For instance, the rate of ADD symptoms among indigenous students from the Brazilian Amazon was found to be $\mathbf{2 4 . 5 \%}$. In Brazilian juvenile offenders, the percentage was $33 \%$. The differences with other studies are discussed considering sampling procedures. In accordance with the tradition of the Roman system, we urgently need Federal specific laws to deal with this public health problem. We must convert into specific laws, the Convention on the Rights of Persons with Disabilities (United Nations) that was recently ratified in Brazil.

Keywords: Handedness; Attention-Deficit/Hyperactivity Disorder; ADD/ADHD; Rights of Persons; Disabilities

\section{INTRODUCTION}

The legal system adopted in Brazil is largely codified on the Roman tradition, and the Federal Government, the States and the Municipalities enact laws. The Federal Constitution [1] is the cornerstone of the Brazilian legislative system, and provides fundamental rights and guarantees for the citizen. In spite of the fact that Brazil ratified the Convention on the Rights of Persons with Disabilities [2], the rights of people suffering from ADD are not specifically protected.

ADD is a genetically determined condition since approximately $75 \%$ of the variability is inattention and hyperactivity in population samples is explained by genetic factors [3]. However, various biological and environmental risk factors also contribute to its etiology, probably exerting their effect through interaction with genetic factors [4].

Epidemiological studies have shown that the ADD worldwide-pooled prevalence was 5.29\% [5]. The prevalence was found to be $19.2 \%$ in South Africa [6], $16.1 \%$ in Colombia [7], and $4 \%$ in Canada [8]. In Brazil we have found different results such as $1.8 \%$ [9], 
$5.8 \%$ [10], 13\% [11], and 17.9\% [12]. No significant differences were found between Europe and North America. There was no substantial difference from studies carried out in other western countries $[7,13]$ as well as in many oriental countries [14-17]. In Japan, the results of a large scale survey of school teachers showed $6.3 \%$ of students with developmental disorder, and $2.5 \%$ of them with ADD [18]. These studies support ADD as an universally valid syndrome.

Handedness and gender are important variables to be considered in neuropsychiatric studies $[19,20]$. Handeness can be evaluated in different ways such as the use of long questionnaires or simply by the hand used to write [20, 21]. In this regard, several studies have demonstrated that among students with learning disabilities, such as dyslexia, autism, and developmental coordination disorder, lefthandedness is more common than in the general population [22-24]. Several studies [25-27] have shown that data derived from parents' reports must be interpreted with caution.

With regard to the use of scales, an American research with 401 pediatricians and family practice physicians, in a prospective cohort study of 22,059 students from 4 to 14 years, showed that $53.5 \%$ of them used school reports to diagnose attentional or hyperactivity problems [28]. Although there was no data available as regards the use of questionnaires by Brazilian physicians and psychologists, it is believed that the use of rating scales to identify students with behavioral and learning problems needs to be emphasized.

In the present investigation, we studied the prevalence of ADD in the state of Rio de Janeiro, Brazil, taking gender and handedness into account.

\section{METHOD}

\subsection{Participants (Table 1)}

A total of 239 students participated in this study. The sample consisted of 120 boys (mean age $=9.17$ years, $\mathrm{SD}=2.51$ years, minimum $=5$ years, maximum $=18$ years) and 119 girls (mean age $=9.11$ years, $\mathrm{SD}=2.76$ years, minimum $=6$ years, maximum $=17$ years), from elementary schools located in four different cities in the State of Rio de Janeiro, Brazil. There was no difference regarding male and female age $(\mathrm{t}=-0.17 ; \mathrm{df}=237 ; \mathrm{p}=$ 0.87).

Considering socio-economic characteristics (particularly educational level), a heterogeneous population can be found in the State of Rio de Janeiro. The Human Development Index (HDI), from the United Nations Development Program (2000), was used to characterize the cities. The HDI is a composite index and three variables are considered for its composite: life expectancy at birth, educational attainment and Gross National Income (GNI)
Table 1. Number of participants.

\begin{tabular}{cccc}
\hline City & $\begin{array}{c}\text { Number of } \\
\text { teachers }\end{array}$ & $\begin{array}{c}\text { Number of } \\
\text { children }\end{array}$ & HDI \\
\hline Petrópolis & 6 & 76 & 0.804 \\
Rio de Janeiro & 4 & 26 & 0.842 \\
São Gonçalo & 10 & 41 & 0.782 \\
São João de Meriti & 25 & 96 & 0.774 \\
$\begin{array}{c}\text { Rio de Janeiro } \\
\text { MetropolitanRegion }\end{array}$ & & & 0.816 \\
Rio de Janeiro State & & & 0.807 \\
Brazil & & & 0.800 \\
Total & 45 & 239 & \\
\hline
\end{tabular}

per capita (PPP US\$). Here, the HDI of each city and the number of participants are described (Table 1).

Forty-five teachers rated the students. The teacher selected to rate a particular student was the one that spent most of the school time with the student in the classroom, and for each student only one teacher answered the questionnaire. It should be mentioned that in the Brazilian educational system, during the first segment of elementary school, in which students are between 6 and 10 years old, school students normally have only one teacher, whereas those in the second segment (aged between 11 and 14) have more than one teacher.

The student's participation in the research was voluntary. Parents and school principals signed informed consents regarding the voluntary participation of the students in the research. The participation of the teachers was also voluntary. This study was approved by the Ethics Committees of the University of the State of Rio de Janeiro (UERJ), protocol 004. 2004, and all participants signed an informed consent before their inclusion in the sample.

\subsection{Measures}

\subsubsection{Evaluation of Hand Preference}

Hand preference was assessed by direct observation of three tasks: 1) hand to write; 2) hand to take a sheet of paper on the table; 3 ) hand to open a lid of a bottle. The choice of the three tasks derived from a previous empirical study of handedness in 1600 Brazilian subjects [29]. The observer that rated the students was blind with respect to the presence or absence of behavioural problems. Then, each student was classified as right-consistent, leftconsistent, or non-consistent. To be consistent the student had to perform the three tasks with the same hand.

\subsubsection{Assessment of Attention Problems and Classification of the Students into Two Groups: Normal-Control and ADD}

The teachers rated the students using the Behavior rating scale - teacher version (BRS-t), developed by Carvalho 
Table 2. Descriptive statistics (participants).

\begin{tabular}{cccc}
\hline & Normal (N = 171) & ADD (N = 68) & Overall \\
\hline \multirow{2}{*}{ Age } & $\mathrm{M}=9.23$ & $\mathrm{M}=8.90$ & $\mathrm{M}=9.14$ \\
& $\mathrm{sd}=2.80$ & $\mathrm{sd}=2.16$ & $\mathrm{sd}=2.63$ \\
Gender & 63 Male $(37 \%)$ & $57 \mathrm{Male}(84 \%)$ & $120 \mathrm{Male}(50 \%)$ \\
& 108 Female $(63 \%)$ & 11 Female $(16 \%)$ & 119 Female $(50 \%)$ \\
& $107(63 \%)$ & $39(57 \%)$ & $146(61 \%)$ \\
& right-consistents & right-consistents & right-consistents \\
Handedness & $7(4 \%)$ & $8(12 \%)$ & $15(6 \%)$ \\
& left-consistents & left-consistents & left-consistents \\
& $57(33 \%)$ & $21(31 \%)$ & $78(33 \%)$ \\
& nonconsistents & nonconsistents & nonconsistents \\
\hline
\end{tabular}

left-consistents + nonconsistents $=$ non-righthanders; $\mathrm{ADD}=$ Attention Deficit Disorder.

et al. [30], composed of 58 questions that are rated on a scale ranging from 1 to 3 , reflecting problem prevalence $(1=$ not true; $2=$ somewhat or sometimes true; $3=$ very true or often true).

A student was classified into the ADD group if he (she) was rated 3 in at least six questions related to impulsivity, hyperactivity, and inattention. These questions derived from the DSM-IV-RT (2000) criteria for ADD. It should be mentioned that there is no discrepancy with DSM V (2013) [31]. The normal-control group was composed of students that did not fulfill the above criteria.

\section{RESULTS}

Sixty-eight students ( $28 \%$ of the total sample) were included in the ADD group (Table 2). The normal-control group included 171 students. The two groups did not differ with regard to age $(t=0.99 ; d f=159 ; p=0.32)$. In contrast, the percentage of males was found to be greater in the ADD group as compared to the normal-control group $\left(\mathrm{X}^{2}=42.956 ; \mathrm{df}=1 ; \mathrm{p}<0.001\right)$.

There was not any significant association $\left(X^{2}=0.558\right.$; $\mathrm{df}=1 ; \mathrm{p}=0.27$ ) between the presence of attention problems and the number of right-consistent and non-righthanders (left consistent and non-consistent students). However, when the analysis was done considering only right-consistent and left-consistent students, the association reached significant levels $\left(X^{2}=4.664 ; \mathrm{df}=1 ; \mathrm{p}=\right.$ 0.03 ). This result can be explained by the higher number of consistent left-handers in the ADD group as compared to the normal-control group. In the normal-control group there was not any significant association between gender and handedness $\left(X^{2}=0.219 ; \mathrm{df}=1 ; \mathrm{p}=0.49\right)$. This indicates that the number of consistent left-handed boys does not differ from the number of left-handed girls in the normal-control group and, as a consequence, the sample was not biased.

\section{DISCUSSION}

The present investigation shows that the number of boys suffering from behavioral problems is higher than the number of girls. The same result has been reported by many other researches [32-34].

Schmidt et al. [35] and Rodriguez et al. [36] have shown that hyperactivity is related to handedness, because left-handers present more problems in impulsive behavior than right-handers. One would argue that the influence of gender on attention problems could be explained by a sample artifact. This would imply that our sample could be biased in favor of left-handed boys. Thus, if this was the case, the association between gender and attention disorders would merely reflect the wellknown effect of handedness since left-handed students present much more behavioral disorders than right-handers. Fortunately, in the normal-control group there was not any significant association between gender and handedness. This indicates that the number of consistent lefthanded boys does not differ from the number of lefthanded girls in the normal-control group, and as a consequence, the sample was not biased. In fact we have even more left-handed girls than left-handed boys. Therefore, the sample was not biased in favour of left-handed boys and the effect of gender on attention cannot be explained by the handedness effect.

The use of rating scales to identify students with behavioral and learning problems needs to be emphasized. The socio-economic aspects of Brazil make the development of teacher behavior rating scales particularly relevant. The low educational level of the population is still an important social problem. At the end of the twentieth century, the average Brazilian over 25 had only 6 years of formal education. In 2001, $13.6 \%$ of the population over 15 years of age were illiterate [37]. Considering these facts, it is common to find parents who have a low educational level or who are even illiterate, and for these people written scales may not be a good way of providing information.

In our study the prevalence of students $(28 \%$ of the total sample) with attention problems is much higher than the figures reported in other studies. This can be explained by the fact that teachers biased the sample in order to incorporate as many as possible students with behavioral problems. Our finding is not different from the study that described the symptoms of ADD among settlement-dwelling indigenous students of the Karajá ethnic group in the Brazilian Amazon [38]. The rate of ADD symptoms among indigenous students from the Brazilian Amazon was 24.5\%. Similarly, Andrade [39] found a high prevalence of ADD (33.3\%) among Brazilian juvenile offenders.

The Brazilian Parliament should promulgate specific laws to protect people suffering from ADD. It is difficult to realize how a country that follows the Roman tradition and ratifies an international convention [2], does not pro- 
mulgate the appropriate laws. Public health authorities should concentrate on early diagnosis and treatment of psychiatric disorders in childhood to reduce future violations. It is also suggested that mental health treatment of detained juveniles should be a fundamental part of the recuperation and reintegration of young offenders into society.

\section{REFERENCES}

[1] Constitution of the Federal Republic of Brazil (1988).

[2] Convention on the Rights of Persons with Disabilities (2006). Organization of the United Nations.

[3] McGough, J.J. and McCracken, J.T. (2000). Assessment of attention-deficit/hyperactivity disorder: A review of recent literature. Current Opinion in Pediatrics, 12, 319324.

http://dx.doi.org/10.1097/00008480-200008000-00006

[4] Rodhe, L.A., Busnello, E.A., Chachamovitch, E., Vieira, G.M., Pinzon, V. and Ketzer, C.R. (1998) Transtorno de déficit de atenção/hiperatividade: Revisando conhecimentos. Revista ABP-APAL, 20, 166-178.

[5] Polanczyk, G., Lima, M.S., Horta, B.L. and Rohde, L.A. (2007) The worldwide prevalence of ADHD: A systematic review and metaregression analysis. The American Journal of Psychiatry, 164, 942-948. http://dx.doi.org/10.1176/appi.ajp.164.6.942

[6] Polanczyk, G. and Jensen, P. (2008) Epidemiologic considerations in attention deficit hyperactivity disorder: A review and update. Child \& Adolescent Psychiatric Clinics of North America, 17, 245-260. http://dx.doi.org/10.1016/j.chc.2007.11.006

[7] Pineda, D.A., Aguirre, D.C., Garcia, M.A., Lopera, F.J., Palacio, L.G. and Kamphaus, R.W. (2005) Validation of tworating scales for attention-deficit hyperactivity disorderdiagnosis in Colombian children. Pediatric Neurology, 33, 15-25. http://dx.doi.org/10.1016/j.pediatrneurol.2005.02.001

[8] Baydala, L., Sherman, J., Rasmussen, C., Wikman, E. and Janzen, H. (2006) ADHD characteristics in Canadian Aboriginal children. Journal of Attention Disorders, 9, 642-647. http://dx.doi.org/10.1177/1087054705284246

[9] Fleitlich-Bilyk, B. and Goodman, R. (2004) Prevalence of child and adolescent psychiatric disorders in southeast Brazil. Journal of the American Academy of Child and Adolescent Psychiatry, 43, 727-734. http://dx.doi.org/10.1097/01.chi.0000120021.14101.ca

[10] Rohde, L.A., Biederman, J., Busnello, E.A., Zimmermann, H., Schmitz, M., Martins, S., et al. (1999) ADHD in a school sample of Brazilian adolescents: A study of prevalence, comorbid conditions, and impairments. Journal of the American Academy of Child and Adolescent Psychiatry, 38, 716-722. http://dx.doi.org/10.1097/00004583-199906000-00019

[11] Fontana, R.S., Vasconcelos, V.M., Werner Jr., J., et al. (2007) ADHD prevalence in four Brazilian public schools. Arquivos de Neuro-Psiquiatria, 65, 134-137.
http://dx.doi.org/10.1590/S0004-282X2007000100027

[12] Guardiola, A., Fuchs, F.D. and Rotta, N.T. (2000) Prevalence of attention-deficit hyperactivity disorders in students. Comparison between DSM-IV and neuropsychological criteria. Arquivos de Neuro-Psiquiatria, 58, 401407. http://dx.doi.org/10.1590/S0004-282X2000000300001

[13] Giel, R., Arango, M.V., Climent, C.E., Harding, T.W., Ibrahim, H.H.A. and Ldrico-Ignacio, L., et al. (1981) Childhood mental disorders in primary health care: Results of observations in four developing countries. Pediatr, 68, 677-683.

[14] Liu, X., Kurita, H., Guo, C., Tachimori, H., Ze, J. and Okawa, M. (2000) Behavioral and emotional problems in Chinesechildren: Teacher reports for ages 6 to 11. The Journal of Child Psychology and Psychiatry, 41, 253260. http://dx.doi.org/10.1017/S0021963099005119

[15] Aramaki, Y. and Uno, H. (2004) Impulsive behaviors inattention-deficit/hyperactivity disorder. No to Hattatsu, 36, 467-472.

[16] Luk, S.L., Leung, P.W. and Lee, P.L.M. (1988) Conners' teacher rating scale in Chinese children in Hong Kong. The Journal of Child Psychology and Psychiatry, 29, 165174. http://dx.doi.org/10.1111/j.1469-7610.1988.tb00701.x

[17] Yao, K.N., Solanto, M.V. and Wender, E.H. (1988) Prevalence of hyperactivity among newly immigrated Chinese-American children. Journal of Developmental \& Behavioral Pediatrics, 9, 367-373. http://dx.doi.org/10.1097/00004703-198812000-00009

[18] Tani, I., Okada, R., Ohnishi, M., Nakajima, S. and Tsujii, M. (2010) Japanese version of the ADHD-RS: An evaluation of its reliability and validity. Research in Developmental Disabilities, 31, 1426-1433. http://dx.doi.org/10.1016/j.ridd.2010.06.016

[19] Schmidt, S.L., Oliveira, R.M., Rocha, F.R. and AbreuVillaça, Y. (2000) Influences of handedness and gender on the Grooved Pegboard Test. Brain and Cognition, 44, 445-454. http://dx.doi.org/10.1006/brcg.1999.1204

[20] Schmidt, S.L., Oliveira, M.R., Krahe, T.E. and Filgueiras, C.C. (2000) The effects of hand preference and gender on finger tapping performance asymmetry by the use of aninfra-red light measurement device. Neuropsychologia, 38, 529-534. http://dx.doi.org/10.1016/S0028-3932(99)00120-7

[21] Annett, M. (1970) A classification of hand preference by association analysis. British Journal of Psychology, 61, 303-321. http://dx.doi.org/10.1111/j.2044-8295.1970.tb01248.x

[22] Cairney, J.C., Schmidt, L.A., Veldhuizen, S., Kurdyak, P., Hay, J. and Faught, B.E. (2008) Left-handedness and developmental coordination disorder. The Canadian Journal of Psychiatry, 53, 696-699.

[23] Egliton, E. and Anett, M. (1994) Handedness and dyslexia: A meta-analysis. Perceptual and Motor Skills, 79, 16111616. http://dx.doi.org/10.2466/pms.1994.79.3f.1611

[24] Goez, H. and Zelnik, N. (2008) Handedness in patients with developmental coordination disorder. Journal of Child 
Neurology, 23, 151-154. http://dx.doi.org/10.1177/0883073807307978

[25] Gartstein, M.A. and Rothbart, M.K. (2003) Studying infant temperament via the revised infant behavior questionnaire. Infant Behavior \& Development, 26, 64-86. http://dx.doi.org/10.1016/S0163-6383(02)00169-8

[26] Mitsis, E.M., McKay, E., Schulz, K.P., Newcorn, J.H. and Halperin, J. (2000) Parent-teacher concordance for DSMIV attention-deficit/hyperactivity disorder in a clinic-referred sample. Journal of the American Academy of Child and Adolescent Psychiatry, 39, 308-313. http://dx.doi.org/10.1097/00004583-200003000-00012

[27] Schmidt, S.L., Snyder, T.J., Roget, A.C. and Gray, E. (2000) Empirical analysis of the selective attention and associated behavior checklists of the Aggregate neurobehavioral student health and educational review. Journal of Developmental Behavioral Pediatrics, 21, 165-171.

[28] Carey, W.B. (1999) Problems in diagnosing attention and activity. Pediatrics, 103, 664-667. http://dx.doi.org/10.1542/peds.103.3.664

[29] Schmidt, S.L. and Höfke, A.A. (1989) Laterality of brazilian adults and its relationship with performance in learning a second language. Society for Neuroscience $A b$ stracts, 15, 1061.

[30] Carvalho, A.L.N., Manhães, A.C. and Schmidt, S.L. (2012) Validity and reliability of a teacher's scale developed in Brazil for assessment of hyperactive/impulsive behaviour and inattention in children and adolescents. Estudos de Psicologia, 29, 481-488.4

[31] American Psychiatric Association (2013) Diagnostic and statistical manual of mental disorders. 5th Edition (DSM5). American Psychiatric Association, Washington DC.

[32] Gershon, J. (2002) A meta-analytic review of gender dif- ferences in ADHD. Journal of Attention Disorders, 5 143-154. http://dx.doi.org/10.1177/108705470200500302

[33] Quinn, P.O. (2008) Attention-deficit/hyperactivity disorder and its comorbidities in women and girls: An evolving picture. Current Psychiatry Reports, 10, 419-423. http://dx.doi.org/10.1007/s11920-008-0067-5

[34] Stefanatos, G.A. and Baron, I.S. (2007) Attention-deficit/ hyperactivity disorder: A neuropsychological perspective towards DSM-V. Neuropsychology Review, 17, 5-38. http://dx.doi.org/10.1007/s11065-007-9020-3

[35] Schmidt, S., Simões, E., Schmidt, G. and Carvalho, A. (2013) The effects of hand preference on attention. Psychology, 4, 29-33. http://dx.doi.org/10.4236/psych.2013.410A006

[36] Rodriguez, A. and Waldenström, U. (2008) Fetal origins of child non-right-handedness and mental health. The Journal of Child Psychology and Psychiatry, 49, 967976. http://dx.doi.org/10.1111/j.1469-7610.2008.01923.x

[37] Henriques, R. (2001) Desigualdade racial no Brasil: Evoluçãodas condições de vida na década de 90 (Texto para discussão807). Rio de Janeiro: IPEEI/MPOG.

[38] Azevêdo, P.V., Caixeta, L., Andrade, L.H.S. and Bordin, I.A. (2010) Attention deficit/hyperactivity disorder symptoms in indigenous children from the Brazilian Amazon. Arquivos de Neuro-Psiquiatria, 68, 541-544. http://dx.doi.org/10.1590/S0004-282X2010000400012

[39] Andrade, R.C., Assumpção, F., Teixiera, I.A. and Fonseca, V.A. (2011) Precalence of psychiatric disorders in juvenile offenders in the city of Rio de Janeiro (RJ, Brazil): Comparison between genders and relation to these verity of the offense. Ciência \& Saúde Coletiva, 16, 2179-2188. http://dx.doi.org/10.1590/S1413-81232011000400017 